\title{
Chloroquine and hydroxychloroquine are associated with reduced cardiovascular risk: a systematic review and meta-analysis
}

This article was published in the following Dove Press journal:

Drug Design, Development and Therapy

\begin{abstract}
Dan Liu, ${ }^{1, *}$ Xiaodan $\mathrm{Li}^{2, *}$ Yonggang Zhang, ${ }^{3}$ Joey SumWing Kwong, ${ }^{4,5}$ Ling Li, ${ }^{6}$ Yiyi Zhang,' Chang Xu, ${ }^{6}$ Qianrui $\mathrm{Li},{ }^{\prime}$ Xin Sun, ${ }^{6}$ Haoming Tian,' Sheyu Li',

'Department of Endocrinology and Metabolism, West China Hospital, Sichuan University, Chengdu 61004I, China; ${ }^{2}$ Department of Gastroenterology, West China Hospital, Sichuan University, Chengdu 6I004I, China; ${ }^{3}$ Center for Stem Cell Research and Application, Institute of Blood Transfusion, Chinese Academy of Medical Sciences \& Peking Union Medical College, Chengdu 610052, China; ${ }^{4}$ Jockey Club School of Public Health and Primary Care, Prince of Wales Hospital, The Chinese University of Hong Kong, Hong Kong; ${ }^{5}$ Department of Clinical Epidemiology and Department of Health Policy, National Center for Child Health and Development, Tokyo, Japan; ${ }^{6}$ Chinese Evidence-based Medicine Center, West China Hospital, Sichuan University, Chengdu 6I004I, China; ${ }^{7}$ Division of Molecular \& Clinical Medicine, Ninewells Hospital, University of Dundee, Dundee, Scotland, UK

*These two authors contributed equally to this work
\end{abstract}

Correspondence: Sheyu Li Department of Endocrinology and Metabolism, West China Hospital, Sichuan University, 37 Guoxue Road, Chengdu 6I004I, Sichuan, China Tel +86 I3। 94874843

Fax +8628 85422982

Email lisheyu@gmail.com
Background and aims: Chloroquine (CQ) and hydroxychloroquine (HCQ) are widely used in patients with rheumatic diseases, but their effects on the cardiovascular system remain unclear. We aimed to assess whether $\mathrm{CQ} / \mathrm{HCQ}$ could reduce the risk of cardiovascular disease (CVD).

Materials and methods: We searched the Cochrane Central Register of Controlled Trials (CENTRAL), PubMed, Embase, and the ClinicalTrials.gov for studies investigating the association between CQ/HCQ and the risk of CVD from inception to 20 December 2017. We carried out the quality assessment using the Newcastle-Ottawa Quality Assessment Scale (NOS). Random-effects model was used to pool the risk estimates relative ratio (RR), hazard ratio (HR) or odds ratio (OR) with $95 \%$ confidence interval (CI) for the outcomes.

Results: A total of 19 studies ( 7 case-control studies, 12 cohort studies, and no clinical trials) involving 19,679 participants were included in the meta-analysis. Pooled results for HRs or RRs showed that CQ/HCQ was associated with a significantly reduced risk of CVD (pooled RR $0.72,95 \%$ CI $0.56-0.94, p=0.013$ ). Results based on ORs showed a similar tendency towards a reduced risk of CVD with CQ/HCQ (pooled OR 0.41, 95\% CI 0.25-0.69, $p=0.001$ ).

Conclusion: Our results suggested that $\mathrm{CQ} / \mathrm{HCQ}$ was associated with a reduced risk of CVD in patients with rheumatic diseases. Randomized trials are needed to confirm the potential of CQ/HCQ in cardiovascular prevention in patients with and without rheumatic diseases.

Keywords: chloroquine, hydroxychloroquine, antimalarials, cardiovascular disease, atherosclerosis, drug repurpose and rheumatic diseases, systematic review

\section{Introduction}

The antimalarial agents such as chloroquine (CQ) and hydroxychloroquine (HCQ) are extensively used in the treatment of many rheumatic diseases, such as systemic lupus erythematosus (SLE) and rheumatoid arthritis (RA). ${ }^{1-3}$ Recently, CQ and HCQ were shown to reduce some traditional cardiovascular risk factors, such as hyperglycemia and hyperlipidemia, in both clinical studies and animal experiments. ${ }^{4-7}$ Despite these promising traits, the association between $\mathrm{CQ} / \mathrm{HCQ}$ and the risk of cardiovascular disease (CVD) is not fully understood. According to the recent systematic review and meta-analysis conducted by Rempenault and colleagues, HCQ has a beneficial effect on metabolic and cardiovascular outcomes in patients with RA, by decreasing modifiable risk factors for CVD, like lipid profile and diabetes incidence. HCQ seemed to decrease the incidence of cardiovascular events, but data were too few for meta-analysis. ${ }^{8}$ Besides this, the potential cardiovascular protection by $\mathrm{CQ} / \mathrm{HCQ}$ was mentioned only in the latest published EULAR recommendations for the management 
of RA, ${ }^{9}$ but not other latest guidelines of rheumatic diseases, cardiovascular diseases and diabetes. ${ }^{10-13}$

In the past few decades, several observational studies, either longitudinal or cross-sectional, investigated the association between $\mathrm{CQ} / \mathrm{HCQ}$ use and cardiovascular outcomes, yielding controversial results. ${ }^{14-32}$ Some studies showed that the use of $\mathrm{CQ} / \mathrm{HCQ}$ reduced the risk of CVD, ${ }^{15,16,21,24,26,29,31}$ whereas others reported a neutral effect. ${ }^{14,17-20,22,23,25,27,28,30,32}$ Given these inconsistencies among trials, we carried out the current study to assess if $\mathrm{CQ} / \mathrm{HCQ}$ was associated with a reduced risk of CVD.

\section{Materials and methods}

The meta-analysis was conducted in accordance with the Meta-Analyses of Observational Studies (MOOSE) ${ }^{33}$ and the Preferred Reporting Items for Systematic Reviews and Meta-Analyses (PRISMA) guidelines. ${ }^{34}$

\section{Literature search}

We conducted a systematic literature search through the Cochrane Central Register of Controlled Trials (CENTRAL), PubMed and Embase for articles published up to 20 December 2017 using the terms "antimalarials" or "hydroxychloroquine" or "chloroquine diphosphate" or "chloroquine" in combination with "heart diseases" or "heart failure" or "heart attack" or "sudden cardiac arrest" or "sudden death" or "ischemic heart disease" or "myocardial infarction" or "myocardial ischemia" or "angina pectoris" or "acute coronary syndrome" or "coronary heart disease" or "coronary artery disease" or "coronary revascularization" or "stroke" or "cardiovascular diseases." The search strategy in PubMed can be seen in Table S1. Results were limited to publications in English. We also searched ClinicalTrials.gov for unpublished data. Reference lists of included articles and relevant systematic reviews were also screened manually to identify potentially eligible publications.

\section{Eligible criteria}

Studies were included if they met the following criteria: 1) designed as a randomized controlled trial (RCT), a cohort study or a case-control study; 2) comparing the risk of CVD between $\mathrm{CQ} / \mathrm{HCQ}$ users and non-users in an RCT or a cohort study or comparing $\mathrm{CQ} / \mathrm{HCQ}$ prescription ratio in patients with and without CVD in a case-control study; 3) relative risk estimates (relative ratio [RR], hazard ratio [HR] or odds ratio [OR] with $95 \%$ confidence interval [CI]) were provided or calculable. For studies of duplicate or overlapping patient populations, only data from the most informative publication with the longest follow-up or with the largest sample size were included. Studies with insufficient data and conference abstracts were excluded.

\section{Data extraction and quality assessment}

Paired investigators independently assessed the eligibility of the studies and extracted the following data from every study using a predefined form: first author, year of publication, study design, study population, sample size, country, age, gender, follow-up duration, drug type, definitions of the cardiovascular outcomes, number of events which occurred during the follow-up period, and risk estimates of CVD with their adjusted covariates. The Newcastle-Ottawa Quality Assessment Scale (NOS) was used to evaluate the quality of each included observational study. ${ }^{35}$ The NOS score ranges from 0 to 9 points, and a higher score indicates higher study quality. Because no RCT investigating the association between CQ/HCQ and CVD was retrieved in our search, no quality assessment tool for RCTs was used in the current study. Discrepancies were resolved by discussion in group conference.

\section{Statistical analysis}

We pooled the risk estimates of outcomes using adjusted ORs, HRs or RRs and their CIs when available. If the adjusted ORs, HRs or RRs were not reported, unadjusted ORs, HRs or RRs and their CIs were employed. When the ORs or RRs with 95\% CIs were not shown directly in a publication, they were calculated by a two-by-two frequency table and the following formulas $(\mathrm{a}, \mathrm{b}, \mathrm{c}, \mathrm{d}, \mathrm{e}, \mathrm{f}){ }^{36}$

$$
\begin{aligned}
& \text { OR }=\frac{a / c}{b / d}=\frac{a d}{b c} \\
& R R=\frac{a /(a+b)}{c /(c+d)} . \\
& \text { Upper 95\% CI }=e^{\ln (O R)+1.96 \sqrt{\left(\frac{1}{a}+\frac{1}{b}+\frac{1}{c}+\frac{1}{d}\right)}} \\
& \text { Lower 95\% CI }=e^{\ln (O R)-1.96 \sqrt{\left(\frac{1}{a}+\frac{1}{b}+\frac{1}{c}+\frac{1}{d}\right)}} \\
& \text { Upper 95\% CI }=e^{\ln (R R)+1.96 \sqrt{\left(\frac{1}{a}+\frac{1}{b}+\frac{1}{c}+\frac{1}{d}\right)}} \\
& \text { Lower 95\% CI }=e^{\ln (R R)-1.96 \sqrt{\left(\frac{1}{a}+\frac{1}{b}+\frac{1}{c}+\frac{1}{d}\right)}}
\end{aligned}
$$

where $\mathrm{a}=$ number of exposed cases; $\mathrm{b}=$ number of exposed non-cases; $c=$ number of unexposed cases; $d=$ number of unexposed non-cases.

To obtain pooled relative risk estimates, we weighted the natural logarithm of the ORs, HRs, and RRs with their 95\% CIs for case-control and cohort studies, respectively, 
by the inverse of their variance. The statistical heterogeneity was assessed using the chi-square test (significant when $p<0.10$ ) and quantified by the $I^{2}$ statistics (significant when $I^{2} \geq 50 \%$ ). Random-effects model was used throughout this meta-analysis in consideration of the clinical heterogeneity. Two subgroup analyses were conducted based on the underlying disease and on whether or not CVD was excluded at baseline. We evaluated potential publication bias by the Begg's test and the Egger's test (significant when $p<0.10$ ). Two types of sensitivity analyses were performed to evaluate the robustness of the results: 1) by omitting studies in which adjusted risk estimates were not available; 2) by using quality-effects model to pool relative risk estimates. ${ }^{37}$ Analyses were performed by STATA statistical software version 12.0 (StataCorp, College Station, TX, USA) and MetaXL version 4.0 (EpiGear International; Wilston, Queensland, Australia).

\section{Results Study selection}

Figure 1 is a summary of the process of study selection. A total of 19,615 potentially eligible papers were identified but 17,754 were excluded by elimination of duplications and screening of the titles and abstracts. After full-text review, another 137 were excluded. Finally, 19 studies involving 19,679 participants were included in this systematic review and meta-analysis.

\section{Study characteristics and quality assessment}

No eligible RCT was identified in the literature screening. Seven of the 19 included studies were designed as casecontrol studies or nesting case-control studies, ${ }^{16,17,22,23,26,30,31}$ and 12 were cohort studies. ${ }^{14,15,18-21,24,25,27-29,32}$

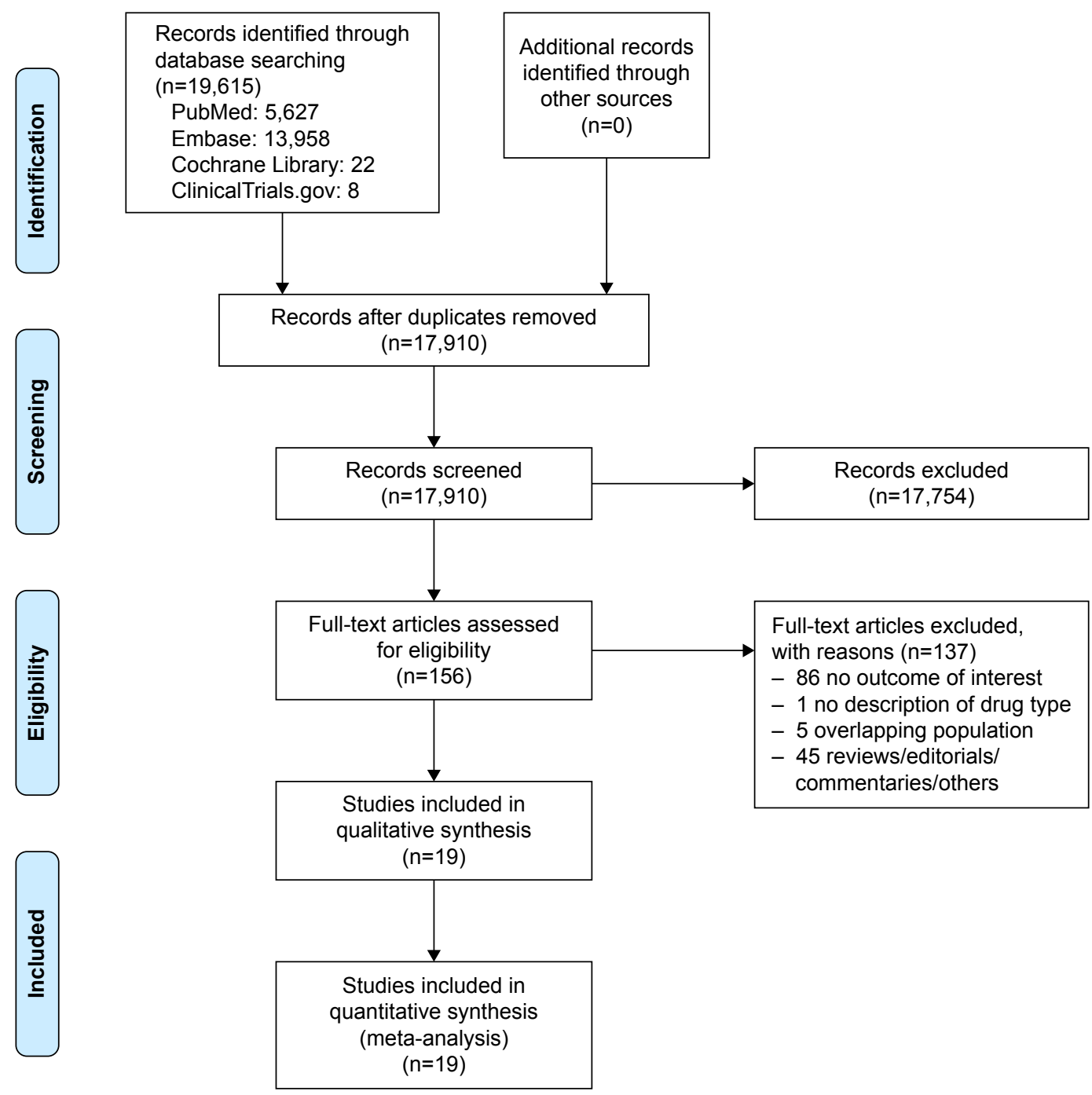

Figure I Flow diagram for study identification and inclusion (Preferred Reporting Items for Systematic Reviews and Meta-Analyses [PRISMA]). 
Table I Characteristics of the included cohort studies

\begin{tabular}{|c|c|c|c|c|c|c|c|c|}
\hline $\begin{array}{l}\text { Study, year, } \\
\text { country }\end{array}$ & $\begin{array}{l}\text { Mean age } \\
\text { (years) }\end{array}$ & $\begin{array}{l}\text { No of } \\
\text { participants }\end{array}$ & $\begin{array}{l}\text { Male } \\
\text { gender, } \\
\text { no (\%) }\end{array}$ & $\begin{array}{l}\text { Study } \\
\text { population }\end{array}$ & $\begin{array}{l}\text { Participants with } \\
\text { CVD, excluded or } \\
\text { not, at enrollment }\end{array}$ & $\begin{array}{l}\text { Drug } \\
\text { type }\end{array}$ & $\begin{array}{l}\text { Follow-up } \\
\text { time (years) }\end{array}$ & $\begin{array}{l}\text { Study } \\
\text { quality } \\
\text { score (NOS) }\end{array}$ \\
\hline van Halm et al, ${ }^{25}$ & 62 (RA without & 613 & $182(29.7)$ & RA & No & $\mathrm{HCQ}$ & NA & 7 \\
\hline 2006 , the & CVD); 67 (RA with & & & & & & & \\
\hline Netherlands & CVD) & & & & & & & \\
\hline $\begin{array}{l}\text { Mok et al, }{ }^{20} 2007 \text {, } \\
\text { China }\end{array}$ & $\begin{array}{l}28.8(\mathrm{LN}) \\
42.7 \text { (PGN) }\end{array}$ & 343 & III (32.4) & LN/PGN & Yes & $\mathrm{HCQ}$ & 8.1 (mean) & 9 \\
\hline $\begin{array}{l}\text { Sisó et al, }{ }^{27} 2008, \\
\text { Spain }\end{array}$ & 31.3 & 206 & $21(10.2)$ & LN & Yes & $\begin{array}{l}\mathrm{HCQ} \\
\text { or CQ }\end{array}$ & 12.3 (mean) & 8 \\
\hline $\begin{array}{l}\text { Becker-Merok et al, } \\
\text { 2009, Norway }\end{array}$ & $\geq 16$ & 158 & $24(15.2)$ & SLE & Yes & $\mathrm{HCQ}$ & 11.9 (mean) & 8 \\
\hline $\begin{array}{l}\text { Gustafsson et al, }{ }^{18} \\
2009, \text { Sweden }\end{array}$ & 45 & 182 & $18(10)$ & SLE & Yes & $\begin{array}{l}\mathrm{HCQ} \\
\text { or CQ }\end{array}$ & 8.3 (mean) & 6 \\
\hline $\begin{array}{l}\text { Nikpour et al, }{ }^{21} 201 \mathrm{l}, \\
\text { Canada }\end{array}$ & 37.1 & 956 & $107(11.2)$ & SLE & Yes & $\begin{array}{l}\mathrm{HCQ} \\
\text { or } \mathrm{CQ}\end{array}$ & 6.7 (mean) & 8 \\
\hline $\begin{array}{l}\text { Magder and Petri, }{ }^{19} \\
2012 \text {, USA }\end{array}$ & 37 & $\mathrm{I}, 874$ & $136(7.3)$ & SLE & Yes & $\mathrm{HCQ}$ & NA & 6 \\
\hline $\begin{array}{l}\text { Arnaud et al, }{ }^{14} 2015 \\
\text { Argentina, France, } \\
\text { Greece, Italy and Spain }\end{array}$ & NA & 191 & NA & SLE & Yes & $\mathrm{HCQ}$ & NA & 5 \\
\hline $\begin{array}{l}\text { Sharma et al, }{ }^{24} \\
2016, \text { USA }\end{array}$ & 56.3 & 1,266 & $313(24.7)$ & Incident RA & Yes & $\mathrm{HCQ}$ & 6.0 (median) & 8 \\
\hline $\begin{array}{l}\text { Hsu et al, }{ }^{28} 2017 \text {, } \\
\text { China }\end{array}$ & 35.3 & 3,892 & $3,404(87.5)$ & $\begin{array}{l}\text { New-onset } \\
\text { SLE }\end{array}$ & Yes & $\mathrm{HCQ}$ & 7.4 (mean) & 9 \\
\hline $\begin{array}{l}\text { Fasano et al, }{ }^{29} \\
2017, \text { Italy }\end{array}$ & 33 & 291 & $20(6.9)$ & SLE & Yes & $\mathrm{HCQ}$ & 8 (median) & 9 \\
\hline $\begin{array}{l}\text { Hung et al, }{ }^{32} 2017 \text {, } \\
\text { China }\end{array}$ & 53.8 & 6,260 & I,866 (29.8) & RA & Yes & $\mathrm{HCQ}$ & 5.39 (median) & 9 \\
\hline
\end{tabular}

Abbreviations: CQ, chloroquine; CVD, cardiovascular disease; HCQ, hydroxychloroquine; LN, lupus nephritis; NA, not available; NOS, the Newcastle-Ottawa Quality Assessment Scale; PGN, primary glomerulonephritis; RA, rheumatoid arthritis; SLE, systemic lupus erythematosus.

The characteristics of included studies are shown in Tables 1 and 2. The NOS score of each study ranged from 5 to 9 . The number of subjects in each study ranged from 58 to 6,260 . Eleven studies provided mean or median time of follow-up, ranging from 5.39 to 12.3 years. ${ }^{15,18,20-22,24,27-30,32}$ All studies were conducted in patients with rheumatic diseases. Four studies recruited patients with RA, ${ }^{24,25,31,32}$
14 studies were conducted in SLE patients, ${ }^{14-19,21-23,26-30}$ one included patients with lupus nephritis or non-lupus primary glomerulonephritis, ${ }^{20}$ and 13 studies excluded patients with a history of CVD. . $^{14,15,18-22,24,27-30,32}$

As shown in Table S2, the CVD investigated was heterogeneous across studies. Variables included for adjustment varied along with the study.

Table 2 Characteristics of the included case-control studies

\begin{tabular}{|c|c|c|c|c|c|c|c|c|}
\hline Study, year, country & $\begin{array}{l}\text { Mean age } \\
\text { (years) } \\
\text { (cases/controls) }\end{array}$ & $\begin{array}{l}\text { No of } \\
\text { participants } \\
\text { (cases/controls) }\end{array}$ & $\begin{array}{l}\text { Male gender, } \\
\text { no }(\%) \\
\text { (cases/controls) }\end{array}$ & $\begin{array}{l}\text { Study } \\
\text { population }\end{array}$ & $\begin{array}{l}\text { Participants } \\
\text { with CVD, } \\
\text { excluded or not, } \\
\text { at enrollment }\end{array}$ & $\begin{array}{l}\text { Drug } \\
\text { type }\end{array}$ & $\begin{array}{l}\text { Follow-up } \\
\text { time (years) }\end{array}$ & $\begin{array}{l}\text { Study } \\
\text { quality } \\
\text { score } \\
\text { (NOS) }\end{array}$ \\
\hline $\begin{array}{l}\text { Roman et al, }{ }^{23} \\
2003 \text {, USA }\end{array}$ & $52 / 39$ & $73 / 124$ & NA & SLE & No & $\mathrm{HCQ}$ & NA & 8 \\
\hline $\begin{array}{l}\text { Bessant et al, }{ }^{16} \\
2006, \text { UK }\end{array}$ & $47.7 / 41.1$ & $29 / 29$ & NA & SLE & No & $\mathrm{HCQ}$ & NA & 7 \\
\hline $\begin{array}{l}\text { de Leeuw et al, }{ }^{17} 2006 \text {, } \\
\text { the Netherlands }\end{array}$ & $48 / 40$ & $13 / 59$ & I (7.7)/8 (13.6) & SLE & No & $\mathrm{HCQ}$ & NA & 7 \\
\hline $\begin{array}{l}\text { Pons-Estel et al, }{ }^{22} \\
2009, \text { USA }\end{array}$ & $48.1 / 35.6$ & $43 / 594$ & II (25.6)/54 (9.1) & SLE & Yes & $\mathrm{HCQ}$ & 6.6 (mean) & 7 \\
\hline Yang et al, ${ }^{26} 2012$, China & $31.4 / 31.2$ & $38 / 38$ & $2(5.3) / 8(21.1)$ & SLE & No & $\mathrm{HCQ}$ & NA & 7 \\
\hline Kao et al, ${ }^{30} 2013$, USA & $51.4 / 43.1$ & $17 / 375$ & $0(0) / 0(0)$ & SLE & Yes & $\mathrm{HCQ}$ & 8 (mean) & 7 \\
\hline Li et al, ${ }^{31} 2017$, China & $68.2 / 53.7$ & $256 / 1,759$ & $85(33.3) / 336(19.1)$ & RA & No & $\mathrm{HCQ}$ & NA & 7 \\
\hline
\end{tabular}

Abbreviations: CVD, cardiovascular disease; $\mathrm{HCQ}$, hydroxychloroquine; NA, not available; NOS, the Newcastle-Ottawa Quality Assessment Scale; RA, rheumatoid arthritis; SLE, systemic lupus erythematosus. 


\begin{tabular}{|c|c|c|c|}
\hline Study ID & & $\operatorname{RR}(95 \% \mathrm{Cl})$ & $\%$ weight \\
\hline Mok et al, ${ }^{20} 2007$ & & $2.03(0.74-5.60)$ & 5.14 \\
\hline Sisó et al, ${ }^{27} 2008$ & & $0.58(0.21-1.62)$ & 5.06 \\
\hline Gustafsson et al, ${ }^{18} 2009$ & & $1.01(0.32-2.67)$ & 4.76 \\
\hline Nikpour et al, ${ }^{21} 2011$ & $\rightarrow$ & $0.50(0.31-0.79)$ & 14.13 \\
\hline Magder and Petri, ${ }^{19} 2012$ & & $0.77(0.54-1.12)$ & 17.36 \\
\hline Arnaud et al, ${ }^{14} 2015$ & & $0.77(0.32-1.84)$ & 6.47 \\
\hline Sharma et al, ${ }^{24} 2016$ & & $0.60(0.41-0.94)$ & 15.72 \\
\hline Hsu et al, ${ }^{28} 2017$ & & $0.58(0.29-1.15)$ & 9.09 \\
\hline Fasano et al, ${ }^{29} 2017$ & & $0.27(0.08-0.86)$ & 3.94 \\
\hline Hung et al, ${ }^{32} 2017$ & & $1.06(0.76-1.49)$ & 18.33 \\
\hline Overall $\left(I^{2}=42.8 \%, p=0.073\right)$ & & $0.72(0.56-0.94)$ & 100 \\
\hline
\end{tabular}

Figure 2 CVD risk in patients receiving $\mathrm{CQ} / \mathrm{HCQ}$ in $\mathrm{HR} / \mathrm{RR}$-reporting studies.

Note: Weights are from random-effects analysis.

Abbreviations: $\mathrm{Cl}$, confidence interval; $\mathrm{CQ}$, chloroquine; $\mathrm{CVD}$, cardiovascular disease; $\mathrm{HCQ}$, hydroxychloroquine; HR, hazard ratio; RR, relative ratio.

\section{Overall meta-analysis}

Nine of the 19 included studies reported the adjusted HRs or RRs with $95 \%$ CIs, ${ }^{14,18-21,24,28,29,32}$ four reported the adjusted ORs with $95 \% \mathrm{CIs}, 23,25,26,31$ and six provided unadjusted ORs with $95 \%$ CIs. ${ }^{15-18,22,30}$ In the overall meta-analysis of HRs or
RRs, CQ/HCQ use in rheumatic patients was associated with a reduced risk of CVD with statistical significance (pooled RR $0.72,95 \%$ CI $0.56-0.94, p=0.013$ ) (Figure 2). The pooled ORs were 0.41 (95\% CI $0.25-0.69, p=0.001)$ (Figure 3) indicating fewer CQ/HCQ prescriptions in CVD patients.

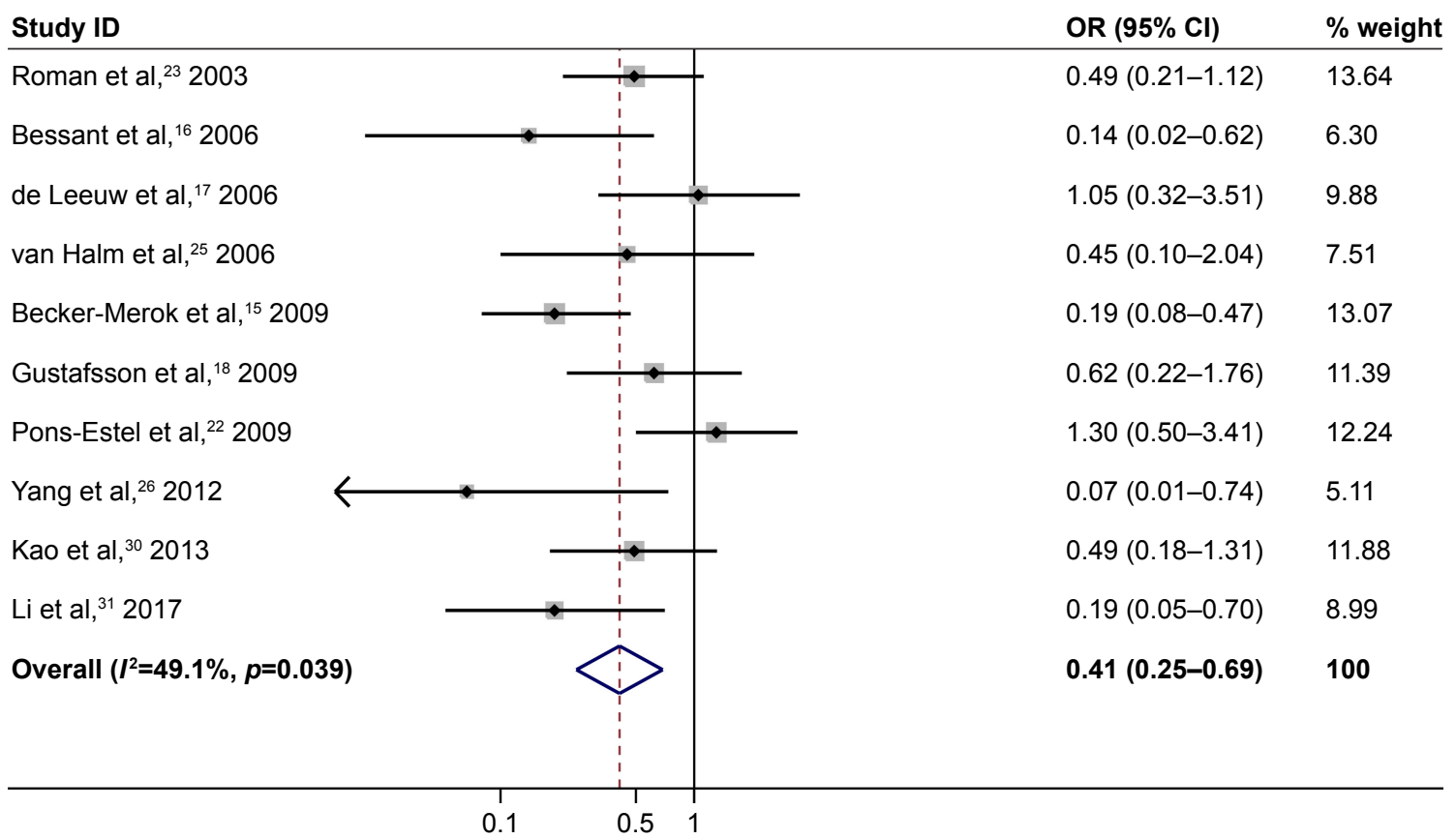

Figure 3 CVD risk in patients receiving $\mathrm{CQ} / \mathrm{HCQ}$ in OR-reporting studies.

Note: Weights are from random-effects analysis.

Abbreviations: $\mathrm{Cl}$, confidence interval; $\mathrm{CQ}$, chloroquine; $\mathrm{CVD}$, cardiovascular disease; $\mathrm{HCQ}$, hydroxychloroquine; OR, odds ratio. 


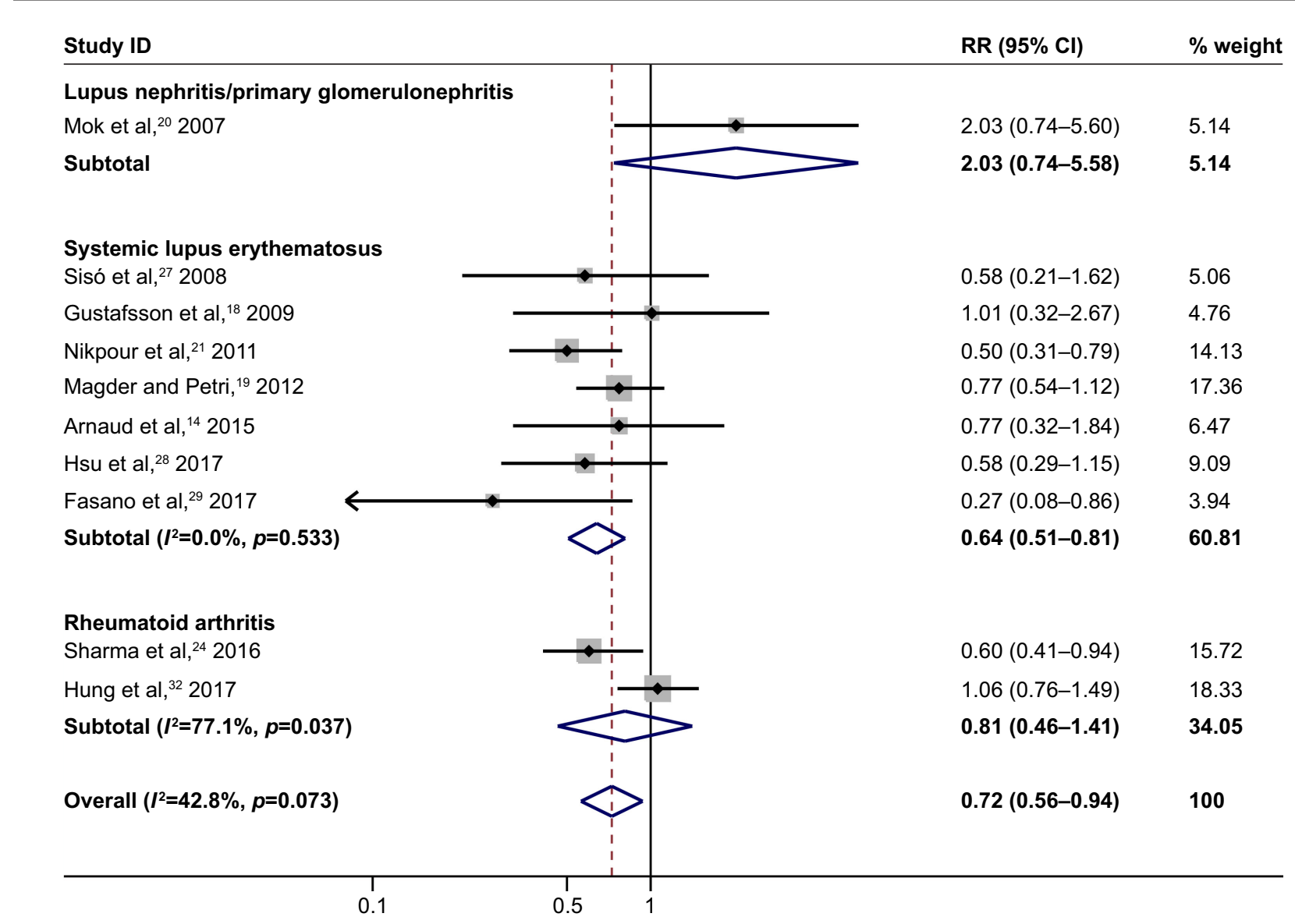

Figure 4 Subgroup analysis based on underlying diseases in HR/RR-reporting studies. Note: Weights are from random-effects analysis.

Abbreviations: $\mathrm{Cl}$, confidence interval; $\mathrm{HR}$, hazard ratio; $\mathrm{RR}$, relative ratio.

\section{Subgroup analyses}

Subgroup analyses were performed based on study population in publications reporting HRs (RRs) or ORs, respectively. CQ/HCQ was associated with a reduced risk of CVD in patients with SLE (RR 0.64, 95\% CI 0.51-0.81), and a similar trend was seen in patients with RA (RR 0.81, 95\% CI 0.46-1.41) but without significant difference. Only one study investigated the association between $\mathrm{CQ} / \mathrm{HCQ}$ and the risk of CVD in patients with lupus nephritis or non-lupus primary glomerulonephritis (RR 2.03, 95\% CI 0.74-5.58) (Figure 4). ${ }^{20}$ The pooled ORs $(95 \% \mathrm{CI})$ of CVD in relation to CQ/HCQ were similar between patients with RA and those with SLE $(0.27$ [0.10-0.74] and 0.44 [0.24-0.80], respectively) (Figure 5).

The other subgroup analysis showed that the pooled ORs in studies excluding or not excluding prior CVD history were 0.52 (95\% CI, 0.23-1.17) and 0.33 (95\% CI, 0.16-0.68), respectively (Figure 6). Since all HR/RR-reporting studies excluded patients with prior CVD at baseline, subgroup analysis for pooled RR was not conducted.

\section{Sensitivity analysis}

We tested the robustness of our results with sensitivity analyses either by excluding studies without adjusted risk estimates or by using quality-effects model. The pooled risk estimates all remained almost unchanged by these two types of sensitivity analyses (Figures S1-S4).

\section{Publication bias}

There was no evidence of publication bias in either the meta-analysis of studies reporting HRs or RRs (Begg's test, $p=0.72$; Egger's test $p=0.67$ ) or in the studies reporting ORs (Begg's test, $p=0.21$; Egger's test $p=0.23$ ). The funnel graphs are shown in Figures $\mathrm{S} 5$ and $\underline{\mathrm{S} 6}$.

\section{Discussion}

Our systematic review involved 19 observational studies with 19,679 CQ/HCQ treated patients and controls. The pooled results for HRs or RRs indicated that CQ/HCQ was associated with an approximately $30 \%$ reduction in the risk of CVD. This effect was comparable to long-term intensive 


\begin{tabular}{|c|c|c|}
\hline Study ID & OR $(95 \% \mathrm{Cl})$ & $\%$ weight \\
\hline $\begin{array}{l}\text { Systemic lupus erythematosus } \\
\text { Roman et al, }{ }^{23} 2003\end{array}$ & $0.49(0.21-1.12)$ & 13.64 \\
\hline Bessant et al, ${ }^{16} 2006$ & $0.14(0.02-0.62)$ & 6.30 \\
\hline de Leeuw et al, ${ }^{17} 2006$ & $1.05(0.32-3.51)$ & 9.88 \\
\hline Becker-Merok et al, ${ }^{15} 2009$ & $0.19(0.08-0.47)$ & 13.07 \\
\hline Gustafsson et al, ${ }^{18} 2009$ & $0.62(0.22-1.76)$ & 11.39 \\
\hline Pons-Estel et al, ${ }^{22} 2009$ & $1.30(0.50-3.41)$ & 12.24 \\
\hline Yang et al, ${ }^{26} 2012$ & $0.07(0.01-0.74)$ & 5.11 \\
\hline Kao et al, ${ }^{30} 2013$ & $0.49(0.18-1.31)$ & 11.88 \\
\hline Subtotal $\left(I^{2}=56.2 \%, p=0.025\right)$ & $0.44(0.24-0.80)$ & 83.50 \\
\hline Rheumatoid arthritis & & \\
\hline van Halm et al, ${ }^{25} 2006$ & $0.45(0.10-2.04)$ & 7.51 \\
\hline Li et al, ${ }^{31} 2017$ & $0.19(0.05-0.70)$ & 8.99 \\
\hline Subtotal $\left(I^{2}=0.0 \%, p=0.396\right)$ & $0.27(0.10-0.74)$ & 16.50 \\
\hline Overall $\left(I^{2}=49.1 \%, p=0.039\right)$ & $0.41(0.25-0.69)$ & 100 \\
\hline
\end{tabular}

Figure 5 Subgroup analysis based on underlying diseases in OR-reporting studies.

Note: Weights are from random-effects analysis.

Abbreviations: $\mathrm{Cl}$, confidence interval; $\mathrm{OR}$, odds ratio.

\begin{tabular}{|c|c|c|}
\hline Study ID & OR $(95 \% \mathrm{CI})$ & $\%$ weight \\
\hline Participants with CVD not excluded at enrollm & & \\
\hline Roman et al, ${ }^{23} 2003$ & $0.49(0.21-1.12)$ & 13.64 \\
\hline Bessant et al, ${ }^{16} 2006$ & $0.14(0.02-0.62)$ & 6.30 \\
\hline de Leeuw et al, ${ }^{17} 2006$ & $1.05(0.32-3.51)$ & 9.88 \\
\hline van Halm et al, ${ }^{25} 2006$ & $0.45(0.10-2.04)$ & 7.51 \\
\hline Yang et al, ${ }^{26} 2012$ & $0.07(0.01-0.74)$ & 5.11 \\
\hline Li et al, ${ }^{31} 2017$ & $0.19(0.05-0.70)$ & 8.99 \\
\hline Subtotal $\left(I^{2}=41.2 \%, p=0.131\right)$ & $0.33(0.16-0.68)$ & 51.42 \\
\hline Participants with CVD excluded at enrollment & & \\
\hline Becker-Merok et al, ${ }^{15} 2009$ & $0.19(0.08-0.47)$ & 13.07 \\
\hline Gustafsson et al, ${ }^{18} 2009$ & $0.62(0.22-1.76)$ & 11.39 \\
\hline Pons-Estel et al, 222009 & $1.30(0.50-3.41)$ & 12.24 \\
\hline Kao et al, ${ }^{30} 2013$ & $0.49(0.18-1.31)$ & 11.88 \\
\hline Subtotal $\left(I^{2}=65.0 \%, p=0.036\right)$ & $0.52(0.23-1.17)$ & 48.58 \\
\hline \multirow[t]{2}{*}{ Overall $\left(I^{2}=49.1 \%, p=0.039\right)$} & $0.41(0.25-0.69)$ & 100 \\
\hline & & \\
\hline 0.1 & & \\
\hline
\end{tabular}

Figure 6 Subgroup analysis based on whether the study excluded the patients with prior CVD at baseline in OR-reporting studies. Note: Weights are from random-effects analysis.

Abbreviations: $\mathrm{Cl}$, confidence interval; CVD, cardiovascular disease; OR, odds ratio. 
blood pressure (25\% reduction in Systolic Blood Pressure Intervention Trial [SPRINT] study) or glucose control (33\% reduction in the United Kingdom Prospective Diabetes Study [UKPDS] study) in large clinical trials and of clinical significance. ${ }^{38,39}$ Our study provides more favorable evidence of the preventive effect of CQ/HCQ on CVD based on the current meta-analysis. ${ }^{8}$

Patients with rheumatic diseases are at higher risk of developing CVD and require primary prevention of CVD..$^{40,41}$ According to our systematic review, the cardiovascular benefit from $\mathrm{CQ} / \mathrm{HCQ}$ was promising based on the following considerations: 1) pooled analyses of RR/HR and OR were consistent, and in accordance with the results from most of the included studies; 2) the pooled results were almost unchanged in the sensitivity analyses; 3 ) no publication bias was found; 4) subgroup analyses showed little difference among different subgroups. Also, the one study excluded from the present meta-analysis, due to not reporting the exact drug, showed results consistent with our analysis. ${ }^{42}$ Mok et al's study was the only exception with an opposite result, in which not only patients with lupus nephritis (162 cases) but also those with non-lupus primary glomerulonephritis (181 cases) were enrolled in the cohort study.$^{20}$ Compared with other studies included in the current meta-analysis, Mok et al's study considered more covariates in the multivariate analysis. Overadjustment could introduce additional bias, which might help explain this inconsistency.

CQ and HCQ are antimalarial drugs and have been widely used for years as antirheumatic drugs due to their safety, efficacy and low cost, indicating their potential in the primary and secondary prevention of CVD in non-rheumatic patients. ${ }^{43,44}$ Adverse events were reported in less than $10 \%$ of patients under antimalarials' treatment. ${ }^{45}$ Gastrointestinal intolerance and cutaneous manifestations are the commonest adverse effects, but they are usually mild and can be released by dose reduction. ${ }^{46} \mathrm{CQ} / \mathrm{HCQ}$-associated cardiotoxicity, presenting as hypotension and arrhythmia, could be serious but is very rare with a routine oral dose. ${ }^{47}$ It was often associated with high-dose or intravenous CQ/HCQ administration or self-poisoning. ${ }^{47}$ Although the mechanism remains unclear, lysosomal disruption and ion channel blockage could be the cause. ${ }^{48}$ High dose and long duration of use of CQ is a confirmed but rare cause of toxic retinopathy, with an incremental risk of less than $1 \%$ in the first 10 years of therapy under a dose of $5.0 \mathrm{mg} / \mathrm{kg} .{ }^{49}$ Considering the rarity of cardiotoxicity and retinopathy, and the significantly reduced risk of CVD exhibited in the current study, CQ/HCQ provided more cardiac benefits than potential risks. ${ }^{50}$ But, careful monitoring is still needed during treatment. Recently, the American Academy of Ophthalmology recommended an annual screening of retinopathy after 5 -year usage of $\mathrm{CQ} / \mathrm{HCQ}$ in low-risk patients. ${ }^{49}$

Previous studies suggested that CQ/HCQ could reduce some cardiovascular risk factors, such as hyperlipidemia, diabetes mellitus, and thrombosis. ${ }^{4-6,51,52}$ Early observations also indicated that HCQ could improve insulin sensitivity, glucose profiles, and glycated hemoglobin (HbAlc) levels in patients with RA and SLE. ${ }^{53-55}$ A randomized trial showed that $\mathrm{CQ} / \mathrm{HCQ}$ could decrease $\mathrm{HbAlc}$ level in non-insulindependent diabetic patients without rheumatic diseases as well. ${ }^{56}$ The underlying mechanism for improving metabolic profiles by CQ/HCQ treatment remains unclear. Possible explanations could be increased affinity of insulin receptors, inhibition of insulin degradation, and increased insulin secretion. ${ }^{57,58}$

$\mathrm{CQ} / \mathrm{HCQ}$ is also associated with beneficial changes of lipid profiles, including decreased levels of total cholesterol, triglycerides, and low-density lipoprotein-cholesterol (LDL-c), irrespective of concomitant steroid use in RA and SLE patients. ${ }^{659-61}$ Possible mechanisms behind the lipidlowering effects of $\mathrm{CQ} / \mathrm{HCQ}$ include increased lipid clearance rate and expression of LDL receptors. ${ }^{62}$

The use of CQ/HCQ has been shown to be thromboprotective. Recently, the risk of thrombosis was observed to be significantly reduced in patients with lupus and antiphospholipid syndrome under $\mathrm{CQ} / \mathrm{HCQ}$ treatment when compared with that in patients not receiving $\mathrm{CQ} / \mathrm{HCQ} .^{51,63,64}$ Several plausible mechanisms have been proposed to help explain the antithrombotic effect of CQ/HCQ, including inhibition of platelet aggregation and reduction of red blood cell aggregation. ${ }^{43,65}$

Ataxia telangiectasia mutated (ATM) protein is a nuclear protein involved in DNA repairing and could be activated by CQ/HCQ. In animal experiments, CQ reduced atherosclerotic lesions in apoE $\mathrm{E}^{-/-}$mice in an ATM-dependent manner. ${ }^{7}$ Our previous study also suggested that polymorphismenhancing gene expression in the promoter region of ATM (rs189037) was associated with less coronary stenosis. ${ }^{66}$ ATM activation is thus a potential molecular mechanism of the anti-atherosclerotic effects of $\mathrm{CQ} / \mathrm{HCQ}$, which still requires further clinical and experimental studies to confirm, and additional mechanisms need exploration in future investigations.

Our meta-analysis had several limitations. Firstly, no RCT reporting the risk estimates of $\mathrm{CVD}$ under $\mathrm{CQ} / \mathrm{HCQ}$ treatment was found. Biases and confounders might be introduced by pooling only observational studies. Hence, we combined the adjusted effect sizes when available to minimize 
these potential biases and confounders. Secondly, since all included studies were carried out in patients with rheumatic diseases, whether CQ/HCQ could reduce the risk of CVD in the non-rheumatic population remains unknown. Regarding the common mechanisms of cardiovascular prevention, randomized cardiovascular outcome trials in non-rheumatic patients are warranted to further illustrate the $\mathrm{CQ} / \mathrm{HCQ}$ potentials of primary and secondary CVD prevention. ${ }^{67}$ Thirdly, since the metabolic indexes data, such as lipid profiles and blood glucose, are not provided in the included studies, investigating the effect of CQ/HCQ on metabolic outcomes is beyond the scope of our current study.

In conclusion, the present meta-analysis based on observational studies showed that the use of CQ/HCQ was associated with a significantly decreased risk of CVD in patients with rheumatic diseases. Given the widespread clinical use of $\mathrm{CQ} / \mathrm{HCQ}$, the potential preventive effect of $\mathrm{CQ} / \mathrm{HCQ}$ on CVD is worth further exploring through RCTs in patients with and without rheumatic diseases, as the reference of future guidelines. Meanwhile, the safety profiles of $\mathrm{CQ} / \mathrm{HCQ}$ require further investigations.

\section{Acknowledgments}

The study was supported by grants from the National Natural Science Foundation of China (Grant No 81400811 and 21534008), National Basic Research Program of China (2015CB942800), the Scientific Research Project of Health and Family Planning Commission of Sichuan Province (Grant No 130029, 150149, 17PJ063 and 17PJ445), Cholesterol Fund by China Cardiovascular Foundation and China Heart House and the International Visiting Program for Excellent Young Scholars of SCU.

\section{Author contributions}

YGZ, HT and SL conceived this study. DL and XL performed the literature search and screening. DL, XL and YYZ extracted the study data. DL, JSWK, LL, CX, QL and XS performed the statistical analysis. DL, XL, QL and SL drafted the manuscript. All authors critically revised the manuscript and agree to be accountable for all aspects of the work.

\section{Disclosure}

The authors report no conflicts of interest in this work.

\section{References}

1. Clark P, Casas E, Tugwell P, et al. Hydroxychloroquine compared with placebo in rheumatoid arthritis. A randomized controlled trial. Ann Intern Med. 1993;119(11):1067-1071.
2. Molad Y, Gorshtein A, Wysenbeek AJ, et al. Protective effect of hydroxychloroquine in systemic lupus erythematosus. Prospective long-term study of an Israeli cohort. Lupus. 2002;11(6):356-361.

3. Tsakonas E, Joseph L, Esdaile JM, et al. A long-term study of hydroxychloroquine withdrawal on exacerbations in systemic lupus erythematosus. The Canadian Hydroxychloroquine Study Group. Lupus. 1998; $7(2): 80-85$.

4. Wasko MC, Hubert HB, Lingala VB, et al. Hydroxychloroquine and risk of diabetes in patients with rheumatoid arthritis. JAMA. 2007; 298(2):187-193.

5. Bili A, Sartorius JA, Kirchner HL, et al. Hydroxychloroquine use and decreased risk of diabetes in rheumatoid arthritis patients. J Clin Rheumatol. 2011;17(3):115-120.

6. Morris SJ, Wasko MC, Antohe JL, et al. Hydroxychloroquine use associated with improvement in lipid profiles in rheumatoid arthritis patients. Arthritis Care Res (Hoboken). 2011;63(4):530-534.

7. Schneider JG, Finck BN, Ren J, et al. ATM-dependent suppression of stress signaling reduces vascular disease in metabolic syndrome. Cell Metab. 2006;4(5):377-389.

8. Rempenault C, Combe B, Barnetche T, et al. Metabolic and cardiovascular benefits of hydroxychloroquine in patients with rheumatoid arthritis: a systematic review and meta-analysis. Ann Rheum Dis. 2018; 77(1):98-103.

9. Smolen JS, Landewe R, Bijlsma J, et al. EULAR recommendations for the management of rheumatoid arthritis with synthetic and biological disease-modifying antirheumatic drugs: 2016 update. Ann Rheum Dis. 2017;76(6):960-977.

10. Singh JA, Saag KG, Bridges SL Jr, et al. 2015 American College of Rheumatology Guideline for the Treatment of Rheumatoid Arthritis. Arthritis Rheumatol. 2016;68(1):1-26.

11. Bertsias G, Ioannidis JP, Boletis J, et al. EULAR recommendations for the management of systemic lupus erythematosus. Report of a Task Force of the EULAR Standing Committee for International Clinical Studies Including Therapeutics. Ann Rheum Dis. 2008;67(2):195-205.

12. Hahn BH, McMahon MA, Wilkinson A, et al. American College of Rheumatology guidelines for screening, treatment, and management of lupus nephritis. Arthritis Care Res (Hoboken). 2012;64(6): 797-808.

13. Ryden L, Grant PJ, Anker SD, et al. ESC Guidelines on diabetes, prediabetes, and cardiovascular diseases developed in collaboration with the EASD: the Task Force on diabetes, pre-diabetes, and cardiovascular diseases of the European Society of Cardiology (ESC) and developed in collaboration with the European Association for the Study of Diabetes (EASD). Eur Heart J. 2013;34(39):3035-3087.

14. Arnaud L, Mathian A, Devilliers H, et al. Patient-level analysis of five international cohorts further confirms the efficacy of aspirin for the primary prevention of thrombosis in patients with antiphospholipid antibodies. Autoimmun Rev. 2015;14(3):192-200.

15. Becker-Merok A, Nossent J. Prevalence, predictors and outcome of vascular damage in systemic lupus erythematosus. Lupus. 2009;18(6): 508-515.

16. Bessant R, Duncan R, Ambler G, et al. Prevalence of conventional and lupus-specific risk factors for cardiovascular disease in patients with systemic lupus erythematosus: a case-control study. Arthritis Rheum. 2006;55(6):892-899.

17. de Leeuw K, Freire B, Smit AJ, Bootsma H, Kallenberg CG, Bijl M. Traditional and non-traditional risk factors contribute to the development of accelerated atherosclerosis in patients with systemic lupus erythematosus. Lupus. 2006;15(10):675-682.

18. Gustafsson J, Gunnarsson I, Börjesson O, et al. Predictors of the first cardiovascular event in patients with systemic lupus erythematosus - a prospective cohort study. Arthritis Res Ther. 2009;11(6):R186.

19. Magder LS, Petri M. Incidence of and risk factors for adverse cardiovascular events among patients with systemic lupus erythematosus. Am J Epidemiol. 2012;176(8):708-719. 
20. Mok CC, Tong KH, To CH, Siu YP, Ho LY, Au TC. Risk and predictors of arterial thrombosis in lupus and non-lupus primary glomerulonephritis: a comparative study. Medicine. 2007;86(4):203-209.

21. Nikpour M, Urowitz MB, Ibanez D, Harvey PJ, Gladman DD. Importance of cumulative exposure to elevated cholesterol and blood pressure in development of atherosclerotic coronary artery disease in systemic lupus erythematosus: a prospective proof-of-concept cohort study. Arthritis Res Ther. 2011;13(5):R156.

22. Pons-Estel GJ, González LA, Zhang J, et al. Predictors of cardiovascular damage in patients with systemic lupus erythematosus: Data from LUMINA (LXVIII), a multiethnic US cohort. Rheumatology. 2009;48(7):817-822.

23. Roman MJ, Shanker BA, Davis A, et al. Prevalence and correlates of accelerated atherosclerosis in systemic lupus erythematosus. $N$ Engl $J$ Med. 2003;349(25):2399-2406.

24. Sharma TS, Wasko MC, Tang X, et al. Hydroxychloroquine use is associated with decreased incident cardiovascular events in rheumatoid arthritis patients. $J$ Am Heart Assoc. 2016;5(1):e002867.

25. van Halm VP, Nurmohamed MT, Twisk JW, Dijkmans BA, Voskuyl AE. Disease-modifying antirheumatic drugs are associated with a reduced risk for cardiovascular disease in patients with rheumatoid arthritis: a case control study. Arthritis Res Ther. 2006;8(5):R151.

26. Yang L, Tao J, Tang X, et al. Prevalence and correlation of conventional and lupus-specific risk factors for cardiovascular disease in Chinese systemic lupus erythematosus patients. J Eur Acad Dermatol Venereol. 2012;26(1):95-101.

27. Sisó A, Ramos-Casals M, Bové A, et al. Previous antimalarial therapy in patients diagnosed with lupus nephritis: influence on outcomes and survival. Lupus. 2008;17(4):281-288.

28. Hsu CY, Lin YS, Su YJ, et al. Effect of long-term hydroxychloroquine on vascular events in patients with systemic lupus erythematosus: a database prospective cohort study. Rheumatology. 2017;56(12):2212-2221.

29. Fasano S, Margiotta DP, Navarini L, et al. Primary prevention of cardiovascular disease in patients with systemic lupus erythematosus: case series and literature review. Lupus. 2017;26(14):1463-1472.

30. Kao AH, Lertratanakul A, Elliott JR, et al. Relation of carotid intimamedia thickness and plaque with incident cardiovascular events in women with systemic lupus erythematosus. Am J Cardiol. 2013;112(7): $1025-1032$

31. Li C, Wang XR, Ji HJ, et al. Cardiovascular disease in rheumatoid arthritis: medications and risk factors in China. Clin Rheumatol. 2017; 36(5):1023-1029.

32. Hung YM, Lin L, Chen CM, et al. The effect of anti-rheumatic medications for coronary artery diseases risk in patients with rheumatoid arthritis might be changed over time: a nationwide population-based cohort study. PLoS One. 2017;12(6):e0179081.

33. Stroup DF, Berlin JA, Morton SC, et al. Meta-analysis of observational studies in epidemiology: a proposal for reporting. Meta-analysis Of Observational Studies in Epidemiology (MOOSE) group. JAMA. 2000;283(15):2008-2012.

34. Moher D, Liberati A, Tetzlaff J, Altman DG; PRISMA Group. Preferred reporting items for systematic reviews and meta-analyses: the PRISMA statement. J Clin Epidemiol. 2009;62(10):1006-1012.

35. Stang A. Critical evaluation of the Newcastle-Ottawa scale for the assessment of the quality of nonrandomized studies in meta-analyses. Eur J Epidemiol. 2010;25(9):603-605.

36. Szumilas M. Explaining odds ratios. J Can Acad Child Adolesc Psychiatry. 2010;19(3):227-229.

37. Doi SA, Thalib L. A quality-effects model for meta-analysis. Epidemiology. 2008;19(1):94-100.

38. SPRINT Research Group; Wright JT Jr, Williamson JD, Whelton PK, et al. A randomized trial of intensive versus standard blood-pressure control. N Engl J Med. 2015;373(22):2103-2116.

39. Holman RR, Paul SK, Bethel MA, Matthews DR, Neil HA. 10-year follow-up of intensive glucose control in type 2 diabetes. $N$ Engl J Med. 2008;359(15):1577-1589.

40. Turesson C, Jacobsson LT, Matteson EL. Cardiovascular co-morbidity in rheumatic diseases. Vasc Health Risk Manag. 2008;4(3):605-614.
41. Symmons DP, Gabriel SE. Epidemiology of CVD in rheumatic disease, with a focus on RA and SLE. Nat Rev Rheumatol. 2011;7(7):399-408.

42. Ahmad Y, Shelmerdine J, Bodill H, et al. Subclinical atherosclerosis in systemic lupus erythematosus (SLE): the relative contribution of classic risk factors and the lupus phenotype. Rheumatology. 2007;46(6):983-988.

43. Ruiz-Irastorza G, Ramos-Casals M, Brito-Zeron P, Khamashta MA. Clinical efficacy and side effects of antimalarials in systemic lupus erythematosus: a systematic review. Ann Rheum Dis. 2010;69(1):20-28.

44. Rynes RI. Antimalarial drugs in the treatment of rheumatological diseases. Br J Rheumatol. 1997;36(7):799-805.

45. Wallace DJ. Antimalarials - the 'real' advance in lupus. Lupus. 2001; 10(6):385-387.

46. Costedoat-Chalumeau N, Dunogué B, Morel N, Le Guern V, GuettrotImbert G. Hydroxychloroquine: a multifaceted treatment in lupus. Presse Med. 2014;43(6 Pt 2):e167-e180.

47. White NJ. Cardiotoxicity of antimalarial drugs. Lancet Infect Dis. 2007;7(8):549-558.

48. Chaanine AH, Gordon RE, Nonnenmacher M, Kohlbrenner E, Benard L, Hajjar RJ. High-dose chloroquine is metabolically cardiotoxic by inducing lysosomes and mitochondria dysfunction in a rat model of pressure overload hypertrophy. Physiol Rep. 2015;3(7):e12413.

49. Marmor MF, Kellner U, Lai TY, Melles RB, Mieler WF. American Academy of Ophthalmology. Recommendations on Screening for Chloroquine and Hydroxychloroquine Retinopathy (2016 Revision). Ophthalmology. 2016;123(6):1386-1394.

50. Wozniacka A, Cygankiewicz I, Chudzik M, Sysa-Jedrzejowska A, Wranicz JK. The cardiac safety of chloroquine phosphate treatment in patients with systemic lupus erythematosus: the influence on arrhythmia, heart rate variability and repolarization parameters. Lupus. 2006;15(8):521-525.

51. Jung H, Bobba R, Su J, et al. The protective effect of antimalarial drugs on thrombovascular events in systemic lupus erythematosus. Arthritis Rheum. 2010;62(3):863-868.

52. Desai RJ, Eddings W, Liao KP, Solomon DH, Kim SC. Disease-modifying antirheumatic drug use and the risk of incident hyperlipidemia in patients with early rheumatoid arthritis: a retrospective cohort study. Arthritis Care Res (Hoboken). 2015;67(4):457-466.

53. Rekedal LR, Massarotti E, Garg R, et al. Changes in glycosylated hemoglobin after initiation of hydroxychloroquine or methotrexate treatment in diabetes patients with rheumatic diseases. Arthritis Rheum. 2010;62(12):3569-3573.

54. Petri M. Hydroxychloroquine use in the Baltimore Lupus Cohort: effects on lipids, glucose and thrombosis. Lupus. 1996;5(Suppl 1):S16-S22.

55. Penn SK, Kao AH, Schott LL, et al. Hydroxychloroquine and glycemia in women with rheumatoid arthritis and systemic lupus erythematosus. J Rheumatol. 2010;37(6):1136-1142.

56. Gerstein HC, Thorpe KE, Taylor DW, Haynes RB. The effectiveness of hydroxychloroquine in patients with type 2 diabetes mellitus who are refractory to sulfonylureas - a randomized trial. Diabetes Res Clin Pract. 2002;55(3):209-219.

57. Bevan AP, Christensen JR, Tikerpae J, Smith GD. Chloroquine augments the binding of insulin to its receptor. Biochem J. 1995;311(Pt 3): 787-795.

58. Kalia S, Dutz JP. New concepts in antimalarial use and mode of action in dermatology. Dermatol Ther. 2007;20(4):160-174.

59. Kerr G, Aujero M, Richards J, et al. Associations of hydroxychloroquine use with lipid profiles in rheumatoid arthritis: pharmacologic implications. Arthritis Care Res. 2014;66(11):1619-1626.

60. Petri M, Lakatta C, Magder L, Goldman D. Effect of prednisone and hydroxychloroquine on coronary artery disease risk factors in systemic lupus erythematosus: a longitudinal data analysis. Am J Med. 1994; 96(3):254-259.

61. Borba EF, Bonfa E. Longterm beneficial effect of chloroquine diphosphate on lipoprotein profile in lupus patients with and without steroid therapy. J Rheumatol. 2001;28(4):780-785.

62. Lange Y, Duan H, Mazzone T. Cholesterol homeostasis is modulated by amphiphiles at transcriptional and post-transcriptional loci. J Lipid Res. 1996;37(3):534-539. 
63. Petri M. Use of hydroxychloroquine to prevent thrombosis in systemic lupus erythematosus and in antiphospholipid antibody-positive patients. Curr Rheumatol Rep. 2011;13(1):77-80.

64. Ruiz-Irastorza G, Egurbide MV, Pijoan JI, et al. Effect of antimalarials on thrombosis and survival in patients with systemic lupus erythematosus. Lupus. 2006;15(9):577-583.

65. Achuthan S, Ahluwalia J, Shafiq N, et al. Hydroxychloroquine's efficacy as an antiplatelet agent study in healthy volunteers: a proof of concept study. J Cardiovasc Pharmacol Ther. 2015;20(2):174-180.
66. Li S, Zhang L, Chen T, et al. Functional polymorphism rs 189037 in the promoter region of ATM gene is associated with angiographically characterized coronary stenosis. Atherosclerosis. 2011;219(2):694-697.

67. Hartman O, Kovanen PT, Lehtonen J, Eklund KK, Sinisalo J. Hydroxychloroquine for the prevention of recurrent cardiovascular events in myocardial infarction patients: rationale and design of the OXI trial. Eur Heart J Cardiovasc Pharmacother. 2017;3(2):92-97.

\section{Publish your work in this journal}

Drug Design, Development and Therapy is an international, peerreviewed open-access journal that spans the spectrum of drug design and development through to clinical applications. Clinical outcomes, patient safety, and programs for the development and effective, safe, and sustained use of medicines are the features of the journal, which has also been accepted for indexing on PubMed Central. The manuscript management system is completely online and includes a very quick and fair peer-review system, which is all easy to use. Visit http://www.dovepress.com/testimonials.php to read real quotes from published authors.

Submit your manuscript here: http://www.dovepress.com/drug-design-development-and-therapy-journal 